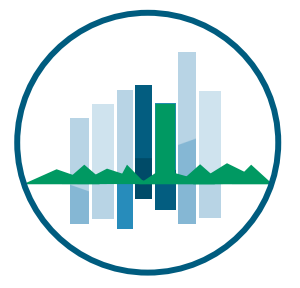

True Smart and Green City?

8th Conference of the

International Forum on Urbanism
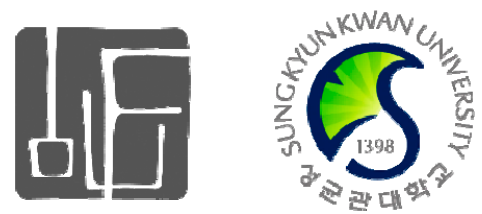

Conference Proceedings Paper

\title{
A Research on Area-Based Urban Governance by Public Participation
}

\section{Xiaowei Zheng, Minghua Huang, Yang Wang and Tian Wang *}

Xi'an University of Architecture and Technology, P.O. Box No. 62, 13 Yanta Road, Beilin District, Xi'an, China

* Author to whom correspondence should be addressed; Tel.: +86-137-0920-2898; Fax: +86-1370920-2898; E-mail: 124452154@qq.com

\begin{abstract}
Transformed from the Western countries, the so called 'area-based urban governance' is an innovative planning strategy in China. In general, it means the establishment of an urban planning and governance system by introducing differentiated spatial policies and institutions for different city areas. This paper focuses on a case study on the implementation of this strategy in inner-city areas, for which public participation was involved in order to achieve the area-based, differentiated urban governance. For Luochuan County, Shaanxi Province, the planners proposed to divide the existing built-up areas into several specified zones for differentiated governance policies. Aiming to improve its feasibility and sustainability, the proposal was discussed, revised and optimized through a 3phase public participation. A model of area-based and participatory urban governance was thus developed in order to balance efficiency and equity in policy making. This model can be regarded as a pilot project to explore a new approach to urban governance and planning implementation in comparable cities.
\end{abstract}

Keywords: Area-Based Urban Governance, Public Participation, Efficiency and Equity, Luochuan County

\section{Introduction}

The urban public policy formulation and implementation in perspective of governance division refers to a space governance system from formulating space policy system with fundamental purpose of facilitating and coordinating the development in different area through differentiated regional 
policies. At the macro level, regional space policy is often combined with regional spatial planning, such as the European Spatial Development Strategy (ESDP), the fifth National Spatial Planning in Netherlands, etc. These policies can be directly converted to space development strategy in order to make different interest groups seize the substantive policy differences and apply them rationally. Ultimately, the urban space policy is systemized by governance division. Presently, foreign practical experience can be referred extensively, while in China, the area which carried on the preliminary attempt and exploration on space governance division can only been found in Guangdong province, (Song Jinsong etc., 2006).

The foreign and domestic practical experience focused on the policy formulation process on macro level of governance division under the thought of special regulation(provincial and municipal level), which provides reference in spatial regulation pattern in the view of regional concept, while few studies on micro-level of central urban area spatial regulation pattern can be rarely discovered. In addition, the development of urban space often reflects as the expansion and governance of space which is unilaterally dominated by the government without consideration on other related interests of different social groups. As a result, space policy implementation progress remains a major problem. With the transition from technical theory to policy device on urban planning and the popularization of participation value, the unilateral government governance behavior has been increasingly incapable to adapt to the complex social interests demand. So, a diversified, multi-channel, multifaceted interest expression in the process of urban construction and management is in urgent need. Above all, to form a new urban management pattern concerning urban center and public interest under the new situation is the key to healthy sustainable urban development.

\section{The Foundation of Public Participation in Urban Spatial Governance Division}

In urban planning, governance is not a new idea, from 1960s Davidoff proposed "Advocacy Planning theory to the repeatedly-mentioned "Public Participation", are all refered to a governance idea aimed at the political and social complexity of the urban planning management.

In the $1960 \mathrm{~s}$, as the awakening of public self-consciousness, social demands on individual rights has risen from the ground. Research on modern urban planning had been influenced by diverse ideas; quite a part of the urban planning researchers chose a practical approach in their research. In such conditions, since the late 1960s, public participation has been widely carried out in the field of urban planning. This kind of reflection on public opinion in urban planning (public participation) is considered a fundamental civil right. In the process of urban planning, public participation should be considered in the discussion and formulation of urban planning policy, especially the voice of the citizen that influenced by the urban planning content. The discussion of planning must include different opinions and reflected in planning and decision making to form an integral planning and action activity, and the public participation in urban planning system is gradually established (Sun Shiwen, 2007). In such background, the urban planning as a public policy formulation process should not be limited to experts or the government, the extensive social masses opinion must be listed in the decision making process. At the same time, the public policy implementation also depends on the collaboration and joint efforts of all the citizens. As a result, the public has the power to understand the urban planning policy, especially the space policy which is closely related to their interests, 
maintaining the embodiment of individual rights. For the relatively insufficient social and economic development area, the whole process of public participation in urban planning formulation becomes more important. This paper is to explore the focus of the study that in the process of urban renewal and update in city center, how to form a setting mechanism which public participation is considered as the core of the urban space Area-Based Urban Governance to set up for different interest groups both on "diversity" and "pertinence", improving the adaptability and flexibility of space policy, so as to guarantee the urban development and the public policy formulation process to effectively performed in public participation.

\section{Empirical Researches (on Area-Based Urban Governance in Perspective of Public Participation)}

\subsection{Research Background}

The selected case city - Luochuan County is located in the middle of Shaanxi province, the typical geomorphic loess plateau, was the only city which is located in the on tableland in this region. With state policy tilt in the western areas and the social and economic development, the urbanization has developed exponentially in Luochuan County. Due to the geographical conditions, economic basis, industrial structure, and the government fiscal constraints, the urban development has faced with some difficulties, among which the most outstanding one shows in the serious social contradictions caused by urban social space stratified differentiation in the process of old city reconstruction. These difficulties both affect the development and transformation of the update of the old city and the development in the new district, which remains a problem faced by most of the county city in China. combined the recent-published Luochuan city Master Plan (2007-2025), and the Regulatory Planning of the Luochuan County, this study explored the Area-Based Urban Governance pattern according to the current situation of urban environment, proposing the research aimed to form a regional space governance policies to improve the development and construction of new district according to the status quo environment (mainly in the old city), safeguarding the fundamental interests and life of the citizens in different social class, improving planning the efficiency and operability and providing a realistic approachfor urban space policy formulation and implementation.

\subsection{Mode Construction - Public Participation in Urban Area-Based Urban Governance}

Based on the previous analysis, the author put forward a periodic process and pattern of public participation in Area-Based Urban Governance. This pattern can be divided into two steps: firstly, a stage benchmark of policies governing division concreted by the planner based on the present situation of urban social and economic development using professional knowledge to achieve environment Area-Based Urban Governance, in this stage, public participation mechanism has not been introduced in policy making process; in the second stage - the public participation stage, which will be a stage calculated and generalized the opinions of the citizens in form of questionnaire, accordingly adjust the control policy and reevaluate them by the feedback from citizens. So after a lot this revaluate circulation, citizen's opinions on the control policy and governance division can gradually achieve accordance, the rationality of the regional boundary will be highly improved, so as to further the 
implement the policy, providing a more realistic and feasible choice making standard. This step and can be divided into three stages of revised feedbacks.

\subsection{Designation Criteria of Area-Based Urban Governance}

In the Area-Based Urban Governance benchmark definition stage, the governor of Luochuan County referred to the experience of Guangdong province. Based on the present situation on urban central area environment, the Area-Based Urban Governance focused on policy control, which embodied in the status quo condition, population density, social structure, historical context and ecological aspects. In the old city reconstruction process, in combination with the coordination between urban and rural areas, ecological safety, social justice, and housing insurance, the governance division policy can be achieved specifically on policy definition, policy subject, policy pattern, and policy content.

\subsection{Rectification and Improvement (of the Area-Based Urban Governance in Perspective of Public} Participation)

Based on the previously mentioned Luochuan County Area-Based Urban Governance formulation model, the public participation mechanism is well established, while the adjustment on Area-Based Urban Governance requires public participation in equal importance, so far as to say that the discretion on the degree and effect of public participation will directly affect the implementation operability in the Area-Based Urban Governance process. In this way, not only the information collection and feedback channels can be effectively enhanced in the related policy making process with better expression on public interests - especially the socially disadvantaged groups but also can effectively unite different interest group into a comprehensive policy framework, so as to avoid the lack of social significance on public participation.

Considering the uncertainty of public participation in different levels, the author divided the governance division process into the following four stages: in the first stage, based on a comprehensive analysis of urban status, the planners formulate corresponding policy and form an urban areas division graph (figure 1a), in this stage, public participation is not considered in the policy making process; in the second stage, the policy content figure is analyzed through the feedback from questionnaire and interview on public opinions, the results of the survey is summarized for the first adjustment both in content and scale on space governance division policy and form space governance policy partition graph (figure 1b) in the second stage; the third stage is the readjustment on the result from the public opinion survey from the second stage using the same method as the previous stage; on this basis, a second Area-Based Urban Governance readjustment figure can be formed according to the second survey results (figure 1c); after three times of public survey feedback, in the last stage, the final space Area-Based Urban Governance pattern can be formulated subjectively (figure 1d). 
Figure 1. (a) Area-Based Urban Governance. (b) Stage 1 Readjustment on Area-Based Urban Governance. (c) Stage 2 Readjustment on Area-Based Urban Governance. (d) Stage 3 Readjustment on Area-Based Urban Governance.

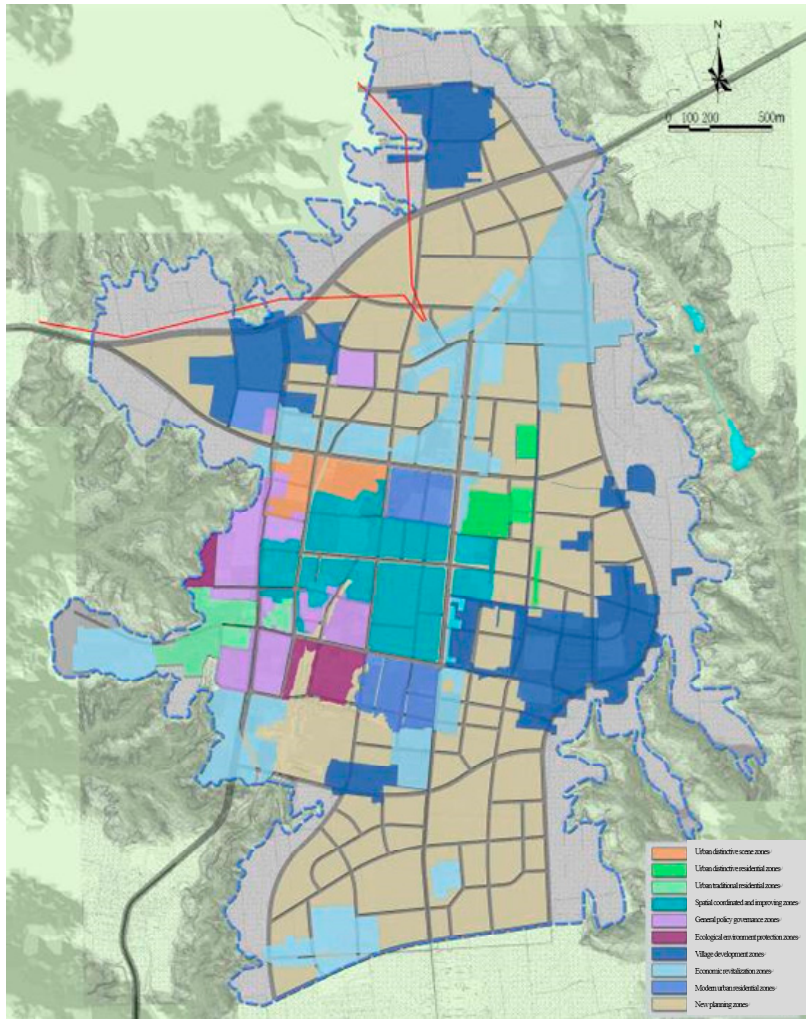

(a)

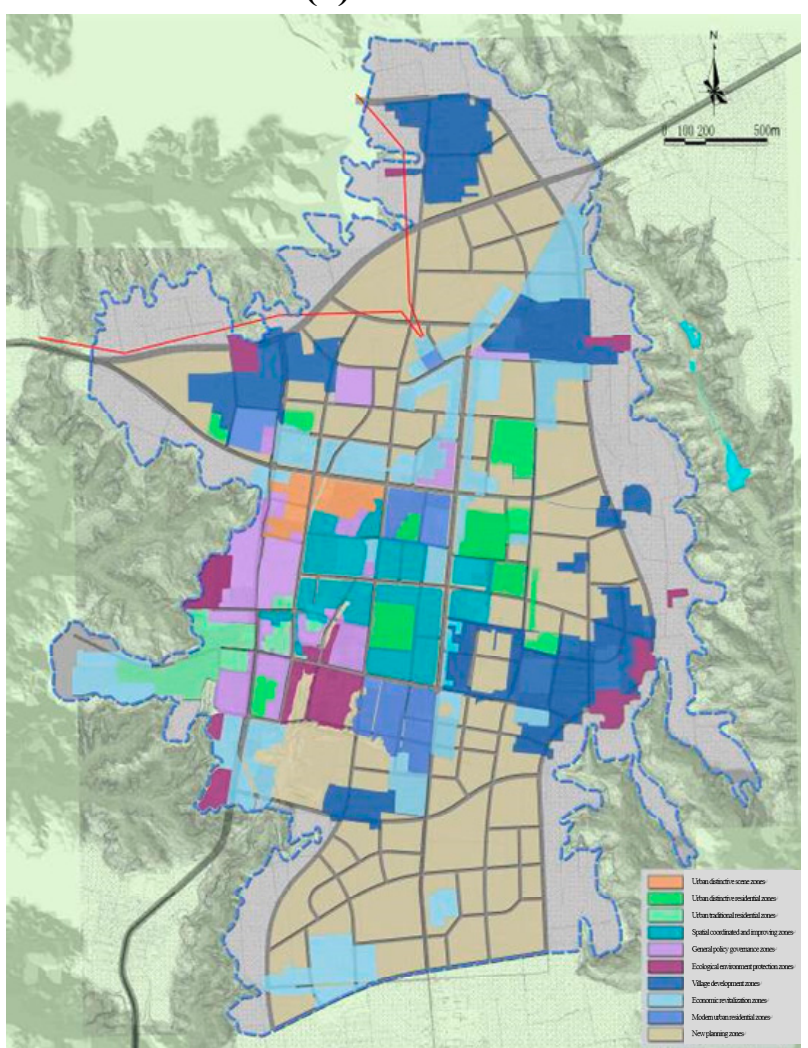

(c)

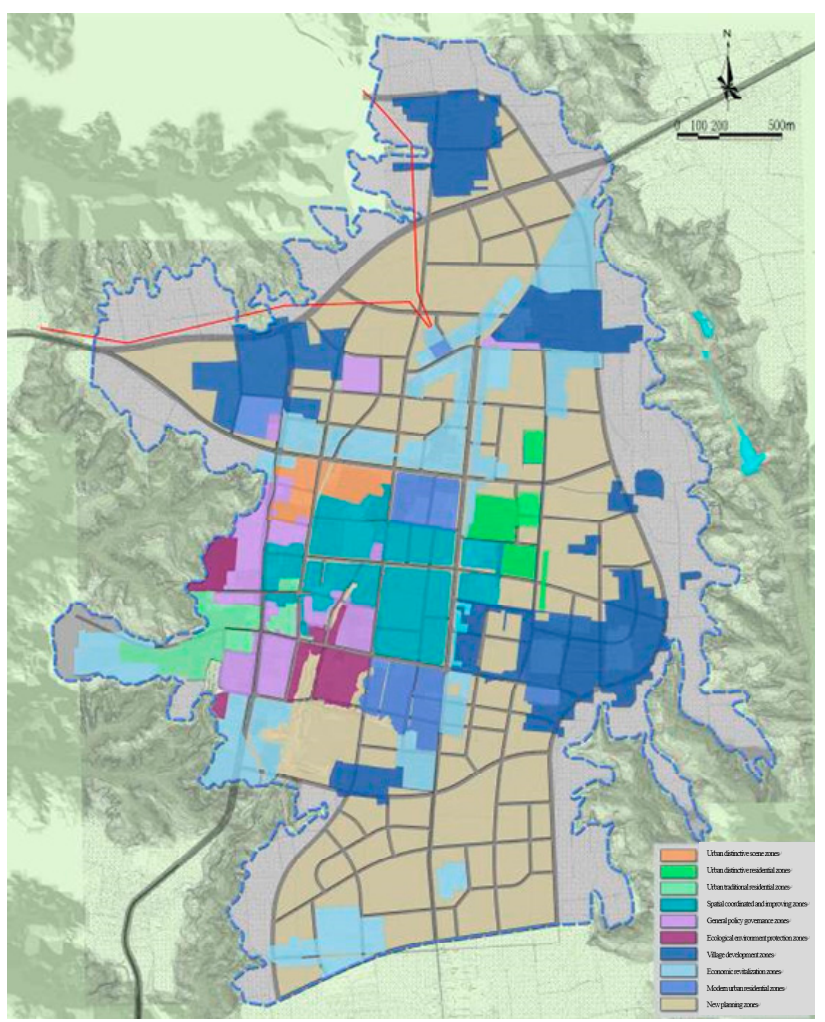

(b)

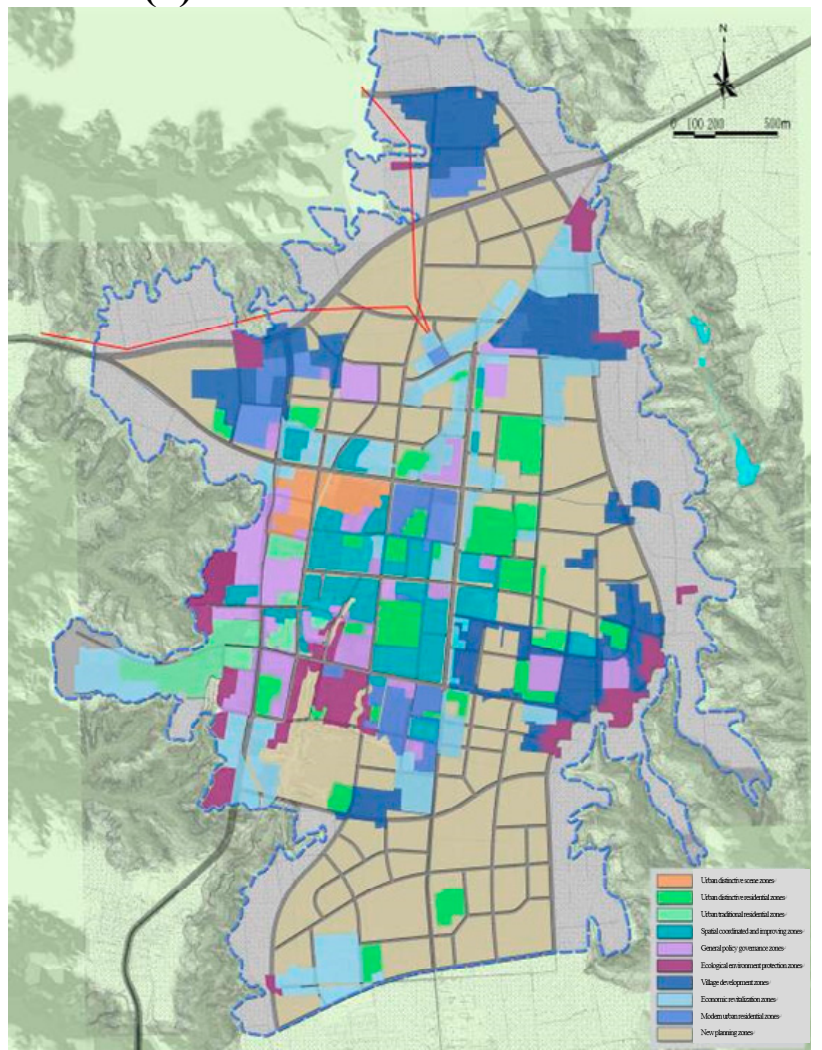

(d) 


\section{Observations on the Public Participation in Area-Based Urban Governance}

Some foreign scholars have divided urban governance model into two patterns: promoting and cooperative (Hong Ming, Yilun $\mathrm{Xu}, 2003$ ). It is obvious that through analysis, the foreign experience of urban governance is a compromise between efficiency and justice. The urban space policy must meet the needs of economic development and safeguard the interests of all social groups, which can be reflected by public participation in decision-making process such as politics, economy and social development. In this case, the Area-Based Urban Governance mode is the organic combination of the previous two kinds of urban governance model, which aids to mainly promote the economy, at the same time ensure the interest of various social groups. In this process, the planner not only plays the role of the main public policy makers, but also the role of coordinator for the interests of all parties.

Not only that, by analyzing the variation of policy division land use ratio in four stages, from the professional view on policy division land use scale of the first stage, the economic revitalization support area $(36.2 \%)$ takes the higher percentage, village development promotion area (19.4\%) and space coordinate area (17.1\%), this three partition occupies $72.7 \%$ of all policy division area, which is the spatial Area-Based Urban Governance development under the guidance of urban economic development. Hence, in Area-Based Urban Governance benchmark defining process, the orientation mainly focused on principle of efficiency. However, with the increase of public participation, the AreaBased Urban Governance land use inclines to vary with the public intention, which an evident principle can be inferred that the Area-Based Urban Governance area of the biggest social interest group (especially the social vulnerable group) is in gradual growth, such as middle-low income security area, traditional residential area.

While the land ratio of the area aimed at development of urban economy and industry, economic revitalization support area, space coordinate area is falling. The land ratio of urban characteristic landscape did remain the same, which shows the concordance on the cognition of city characteristic between the planner and urban residents. In addition, the land ratio of ecological and environmental conservation area also increased significantly, proving that urban residents' awareness on environmental protection and willing to jointly maintain the urban ecological environment. In short, through three rounds of public participation survey in the process of policy formulation and revision of Luochuan County, the improvement of division policy can not only be found in the urban planning process, but also for the "division" which embodied in the social level, balancing the idea of urban public policy governance on "justice" and "efficiency.

\section{Conclusions}

Political governance is indeed a society management process to maximize the public interest, which refers to the "good governance" in western countries, the return of the state power to the society; good governance is the process of power return to the people (Xi Huan, 2003). In this sense, the civil society is the foundation of good governance. In the process of urban planning administration, only to establish a social-oriented foundation can prove the connotation of a fully-developed civil society through specific public policy organization achieve the economic development and at the same time protect the interests of different social group. In this paper, through empirical study, the author 
proposed to establish an environmental Area-Based Urban Governance pattern focused on both equity and efficiency on micro level with primary concern on public participation and space policy, hoping to provide a practical solution and exploration on policy management and urban planning implementation. The urban space development policy formulation pattern can be further enlightened and discussed.

\section{Acknowledgments}

National Natural Science Foundation of China project_— "Interval Form" Control of the Development Intensity of Large and Medium-sized Cities' Mew Area in Northwest under Achievements ( No. 51378413)

\section{References and Notes}

1. Hong Ming; Xu Yilun. The Discussion on the Governance and the small town in China. City Planning Review 2001, 9, 37-41.

2. Song Jinsong; Luo Xiaohong. From regional Greenland to policy zoning: Change of Urban-Rural spatial Governance in Guangdong. City Planning Review 2006, 11, 51-57.

(C) 2015 by the authors; licensee MDPI and IFoU, This article is an open access article distributed under the terms and conditions of the Creative Commons Attribution license. 